\title{
Correction to: Designing a fuzzy decision support framework for assessing solid waste management in the South European region
}

\author{
Dragan Pamučar ${ }^{1} \cdot$ Moein Behzad $^{2} \cdot$ Darko Božanić $^{3} \cdot$ Masoud Behzad $^{4}$
}

Published online: 14 February 2022

๑) Springer-Verlag GmbH Germany, part of Springer Nature 2022

\section{Correction to: Environmental Science and Pollution Research} https://doi.org/10.1007/s11356-022-18891-y

In page 10, Expert 3 equation 5,6,6 should be 5,6,7. Expert 4 equation, the subscript should be 1 not 6 in line 1,3,5.

The Original article has been corrected.

Publisher's note Springer Nature remains neutral with regard to jurisdictional claims in published maps and institutional affiliations.

The original article can be found online at https://doi.org/10.1007/ s11356-022-18891-y.

Masoud Behzad

masoud.behzad@uv.cl

1 Department of Logistics, Military academy, University of Defence, Belgrade, Serbia

2 Department of Social Planning, Faculty of Social Sciences, University of Allameh Tabataba'i, Tehran, Iran

3 Military Academy, University of Defence, Belgrade, Serbia

4 School of Industrial Engineering, Faculty of Engineering, Universidad de Valparaíso, Valparaíso, Chile 